\title{
Multiple DNA Markers for Identification of Xanthomonas arboricola pv. juglandis Isolates and its Direct Detection in Plant Samples
}

\begin{abstract}
Camila Fernandes, CIBIO - Centro de Investigação em Biodiversidade e Recursos Genéticos, InBIO, Laboratório Associado, Universidade do Porto, Vairão, Portugal; INIAV - Instituto Nacional de Investigação Agrária e Veterinária, Av. da República, Quinta do Marquês, Oeiras, Portugal; and FCUP - Faculdade de Ciências, Departamento de Biologia, Rua do Campo Alegre S/n ${ }^{\circ}$ Universidade do Porto, Porto, Portugal; Pedro Albuquerque, CIBIO - Centro de Investigação em Biodiversidade e Recursos Genéticos, InBIO, Laboratório Associado, Universidade do Porto, Vairão, Portugal; Rui Sousa, INIAV - Instituto Nacional de Investigação Agrária e Veterinária, Polo de Alcobaça, Estrada de Leiria, Alcobaça, Portugal; Leonor Cruz, INIAV - Instituto Nacional de Investigação Agrária e Veterinária, Av. da República, Quinta do Marquês, Oeiras, Portugal; and BioISI - Instituto de Biossistemas e Ciências Integrativas, Campus da FCUL, Campo Grande, Lisboa, Portugal; and Fernando Tavares, CIBIO - Centro de Investigação em Biodiversidade e Recursos Genéticos, InBIO, Laboratório Associado, Universidade do Porto, Vairão, Portugal; and FCUP - Faculdade de Ciências, Departamento de Biologia, Rua do Campo Alegre $\mathrm{S} / \mathrm{n}^{\circ}$ Universidade do Porto, Porto, Portugal
\end{abstract}

\begin{abstract}
Xanthomonas arboricola pv. juglandis (Xaj) is the etiological agent of walnut (Juglans regia L.) bacterial blight (WBB), and has been associated to other walnut emerging diseases, namely brown apical necrosis (BAN) and vertical oozing canker (VOC), altogether severely affecting the walnut production worldwide. Despite the research efforts carried out to disclose Xaj genetic diversity, reliable molecular methods for rapid identification of $X a j$ isolates and culture-independent detection of $X a j$ in infected plant samples are still missing. In this work, we propose nine novel specific DNA markers (XAJ1 to XAJ9) selected by dedicated in silico approaches to identify $X a j$ isolates and detect these bacteria in infected plant material. To confirm the efficacy and specificity of these markers, dot blot hybridization was carried out across a large set of xanthomonads. This analysis, which confirmed the pathovar specificity of these markers, allowed to identify four broad-range markers (XAJ1, $\mathrm{XAJ} 4, \mathrm{XAJ6}$, and XAJ8) and five narrow-range markers (XAJ2, $\mathrm{XAJ} 3, \mathrm{XAJ} 5, \mathrm{XAJ}$, and XAJ9), originating 12 hybridization patterns

(HP1 to HP12). No evident relatedness was observed between these hybridization patterns and the geographic origin from which the isolates were obtained. Interestingly, four isolates that clustered together according the gyrB phylogenetic analysis (CPBF 1507, 1508, 1514, and 1522) presented the same hybridization pattern (HP11), suggesting that these nine markers might be informative to rapidly discriminate and identify different $X a j$ lineages. Taking into account that a culture-independent detection of Xaj in plant material has never been described, a multiplex PCR was optimized using markers XAJ1, XAJ6, and XAJ8. This triplex PCR, besides confirming the dot blot data for each of the $52 \mathrm{Xaj}$, was able to detect $X a j$ in field infected walnut leaves and fruits. Altogether, these nine $X a j$-specific markers allow conciliating the specificity of DNAdetection assays with typing resolution, contributing to rapid detection and identification of potential emergent and acutely virulent $X a j$ genotypes, infer their distribution, disclose the presence of this phytopathogen on potential alternative host species and improve phytosanitary control.
\end{abstract}

Xanthomonas arboricola (Vauterin et al. 1995) is a bacterial species responsible for economically relevant diseases in several important fruit trees (Frutos 2010; Lamichhane 2014). According to host specificity, several pathovars of $X$. arboricola are presently acknowledged (Fischer-Le Saux et al. 2015; Janse et al. 2001; Vauterin et al. 1995). Among these, pathovar juglandis has been considered as one of the most serious threats to walnut production worldwide (Belisario et al. 2002; Hajri et al. 2010; Lamichhane 2014; Moragrega and Ozaktan 2010). X. arboricola pv. juglandis (Xaj) was first described in the beginning of the 20th century (Pierce 1901), and it was since identified as the etiological agent of walnut bacterial blight (WBB), the most well-known disease of walnut (Juglans sp.), often recognized by the presence of necrotic spots on leaves and fruits (Smith et al. 1912). Xaj has been also frequently associated to brown apical necrosis (BAN) characterized by apical necrotic lesions near the blossom end of the nut, which has also been associated with other phythopathogens (Belisario et al. 2002; Moragrega and Ozaktan

Corresponding author: Fernando Tavares; E-mail: ftavares@fc.up.pt

*The $\boldsymbol{e}$-Xtra logo stands for "electronic extra" and indicates that one supplementary table and three supplementary figures are available online.

Accepted for publication 10 January 2017.

(c) 2017 The American Phytopathological Society
2010; Moragrega et al. 2011), and vertical oozing canker (VOC), consisting of unusual symptoms, including vertical cankers, deformations, and brown exudates, which appear mainly on the trunk of walnut trees (Hajri et al. 2010). While different parts of the plant can be infected, leading to a decrease of tree vigor, the main economic impact of diseases attributed to $X a j$ is the substantial yield losses, due to a premature fruit drop and a decrease of the quality of marketable nuts (Lamichhane 2014; Scortichini 2010).

Occurrence of Xaj infection has been observed worldwide (Frutos 2010 ) with a recent increase in the number of outbreaks reported in different walnut production regions (Hajri et al. 2010; Lamichhane 2014; Moragrega et al. 2011). The impact of more frequent and severe outbreaks affecting the main producing countries is still unknown. Thus, further understanding of pathogen biology and epidemiology is crucial for the effective control of the disease (Lamichhane 2014; Scortichini 2010). Studies have shown that Xaj can multiply epiphytically, and penetrate and invade walnut trees during favorable conditions, mainly through stomata structures, leaf-scars, or plant wounds (Lamichhane 2014; Scortichini 2010). It has also been described that dormant buds are privileged overwintering sites for Xaj (Lindow et al. 2014; Mulrean and Schroth 1982). Furthermore, the existence of alternative host reservoirs of Xaj, such as asymptomatic plant species, might also be relevant for the dissemination and transmission of Xaj to walnut plants (Allen et al. 2009; Lamichhane 2014).

Currently, diagnostic procedures for Xaj rely on traditional methods based on bacteria isolation using differential or semiselective media, species-specific biochemical assays, and pathogenicity tests (Janse 2010; Moragrega 2012). Despite the numerous DNA-based typing 
methods for genetic characterization of Xaj populations that have been proposed in recent years (Burokiene and Pulawska 2012; Essakhi et al. 2015; Giovanardi et al. 2016; Hajri et al. 2010; Ivanović et al. 2015; Kałużna et al. 2014; Marcelletti et al. 2010), reliable molecular methods for rapid identification of Xaj isolates and culture-independent detection of $X a j$ in infected plant samples are still missing. Nonetheless, there are a few studies that report identification of Xaj isolates by PCR amplification of a single marker (Burokiene and Pulawska 2012; Gironde et al. 2009; Ivanović et al. 2015; Kałużna et al. 2014; Moragrega 2012), but neither the sequence of the marker nor the primers were made available, making difficult a broad assessment of this method.

To overcome some of these limitations, this study focused on the selection and validation of unique and discriminative $X a j$ genomic regions. These DNA markers, besides providing the tools for culture-independent detection of $X a j$ in infected plant material, and for the reliable identification of isolates, will certainly be useful to disclose the presence of this phytopathogen on potential alternative host species, contributing to detail the life cycle of these bacteria and helping to design the most suitable phytosanitary strategies for prevention and containment of diseases caused by Xaj.

\section{Materials and Methods}

Selection of specific DNA markers for Xaj. The identification of $X a j$-specific DNA regions was carried out through the analysis of all possible ORFs (open reading frames) retrieved from the concatenated contigs of Xaj strain NCPPB 1447 draft genome (accession PRJNA84273) using Geneious v. 7.1.2 software (Biomatters, Auckland, New Zealand). A BLAST analysis (Altschul et al. 1990) was performed in order to infer the Xaj specificity of each ORF. Sequences with the best BLAST specificity results were chosen as the most promising regions for marker design (Table 1).

For DNA marker selection, the $X a j$-specific ORFs were further screened for their putative function and for their suitability to design primer pairs using the Vector NTI 10 software (Invitrogen, Carlsbad, CA) favoring high PCR stringency, in order to prevent unspecific amplification and facilitate multiplexing. These premises resulted in nine putative $X a j$-specific markers and corresponding primers pairs (XAJ1 to XAJ9), which were chosen for further experimental validation using bacterial reference strains and isolates (Table 1).

Bacterial strains, culture conditions, and DNA extraction. The bacterial strains used for validation of the nine putative $X a j$-specific markers are listed in Table 2, and include 18 strains of Xaj, five strains representing the pathovars celebensis, corylina, fragariae, populi, and pruni of $X$. arboricola, as well as 12 strains belonging to other species of Xanthomonas. Bacterial strains were cultured in yeast extract glucose carbonate (YGC) medium (yeast extract, $5.0 \mathrm{~g}$; glucose, $10.0 \mathrm{~g} ; \mathrm{CaCO}_{3}, 30.0 \mathrm{~g}$; agar, $15.0 \mathrm{~g}$; distilled water up to 1.0 liter) at $28^{\circ} \mathrm{C}$, except for $X$. fragariae, which was cultured in yeastpeptone-glucose agar (YPGA) medium (yeast extract, $5.0 \mathrm{~g}$; bacto peptone, $5.0 \mathrm{~g}$; glucose, $10.0 \mathrm{~g}$; agar, $15.0 \mathrm{~g}$; distilled water up to 1.0 liter) at $20^{\circ} \mathrm{C}$.

DNA was extracted from pure cultures using the EZNA Bacterial DNA Purification kit (Omega Bio-Tek, Norcross, GA), according to the manufacturer's instructions, and quantified using the Qubit 2.0 Fluorometer HS Assay (Invitrogen, Carlsbad, CA).

Isolation of bacteria from walnut leaves and fruits with WBB and BAN symptoms. Leaf and fruit samples of walnut trees (Juglans regia) showing WBB and/or BAN symptoms were collected during the spring-summer seasons, from six geographic regions of Portugal (Alcobaça, Azeitão, Beja, Estremoz, Loures, and Seia) (Table 3).

Putative $X a j$ were isolated from infected leaves and fruits by using a sterile scalpel to excise plant tissue adjacent to necrotic areas. Sampled plant fragments were disinfected by immersion in $70 \%$ ethanol for 30 s, thoroughly washed with sterile distilled water (SDW), and then macerated with $5 \mathrm{ml}$ of SDW in extraction bags (Bioreba AG, Reinach, Switzerland). The resulting suspensions and the correspondent $10^{-1}$ dilutions were streaked on yeast extract dextrose carbonate (YDC) medium (yeast extract, $10.0 \mathrm{~g}$; dextrose, $20.0 \mathrm{~g}$; $\mathrm{CaCO}_{3}, 20.0 \mathrm{~g}$; agar, $15.0 \mathrm{~g}$; distilled water up to 1.0 liter) and incubated at $26 \pm 2{ }^{\circ} \mathrm{C}$ for 4 days (Lelliott and Stead 1987). Characteristic mucoid yellow colonies were streaked on fresh nutrient agar medium to ensure purity. All isolates were stored at $-80^{\circ} \mathrm{C}$ at the Portuguese Collection of Phytopathogenic Bacteria (CPBF - Colecção Portuguesa de Bactérias Fitopatogénicas). Bacterial DNA was extracted using EZNA Bacterial DNA Purification kit.

Symptomatic walnut leaves and fruits were additionally used for culture-independent detection of Xaj by multiplex PCR. Total DNA was extracted from pelleted cells using $2 \mathrm{ml}$ of the plant suspensions obtained as described above and centrifuged at $16,000 \times g$ for 10 min. DNA extraction was performed using both the QIAGEN DNeasy Plant Mini kit, following manufacturer's instructions (Qiagen, Hilden, Germany) and the CTAB-based DNA extraction method (Doyle 1991; Murray and Thompson 1980). To confirm Xaj as the causal agent of infection in these plant samples, bacterial isolates were obtained following the procedure described above.

Molecular analysis of isolates by gyrB. The identification of the bacterial isolates was carried out by amplification and sequencing of the $g y r B$ gene as previously described by Young et al. (2008), using the primers XgyrB1F and XgyrB1R and a reaction mixture containing $1 \times$ DreamTaq Buffer with $2.0 \mathrm{mM}$ $\mathrm{MgCl}_{2}$ (Fermentas, Ontario, Canada), $0.2 \mathrm{mM}$ of each dNTP (Fermentas), $0.2 \mu \mathrm{M}$ of each primer, 1U of DreamTaq DNA Polymerase (Fermentas), and $25 \mathrm{ng}$ of DNA template. gyrB

Table 1. Xanthomonas arboricola pv. juglandis specific markers, corresponding primer pair sequences, and expected amplicon sizes. The best BLAST hits (blastn and wgs) are indicated for each marker

\begin{tabular}{|c|c|c|c|c|c|}
\hline \multirow[b]{2}{*}{ Markers } & \multirow[b]{2}{*}{ Primers } & \multirow[b]{2}{*}{ Sequences $\left(5^{\prime}-3^{\prime}\right)$} & \multirow[b]{2}{*}{ Length (bp) } & \multicolumn{2}{|c|}{ Best BLAST hit ( $\mathrm{E}$ value/Q coverage) $)^{\mathrm{a}}$} \\
\hline & & & & blastn & wgs blast \\
\hline \multirow[t]{2}{*}{$\overline{\mathrm{XAJ} 1}$} & XAJ1F & GTTGTCAAGGTCGCTACTGGACGC & \multirow[t]{2}{*}{758} & X. campestris 17 & \multirow{2}{*}{$\begin{array}{l}\text { X. arboricola pv. celebensis NCPPB } 1832 \\
(0 / 100 \%)\end{array}$} \\
\hline & XAJ1R & CGACAGGTACCGAAAGTGGACG & & $(2 \mathrm{e}-08 / 12 \%)$ & \\
\hline \multirow[t]{2}{*}{$\mathrm{XAJ} 2$} & $\mathrm{XAJ} 2 \mathrm{~F}$ & AGATCGGGCTGGATGAAGAAGAG & \multirow[t]{2}{*}{753} & Desulfomicrobium baculatum DSM 4028 & \multirow{2}{*}{$\begin{array}{l}X . \text { perforans } \mathrm{TB} 15 \\
(0 / 100 \%)\end{array}$} \\
\hline & $\mathrm{XAJ} 2 \mathrm{R}$ & CCAGGATCGCAAGTTCTTCAAGTG & & $(4 \mathrm{e}-12 / 17 \%)$ & \\
\hline \multirow[t]{2}{*}{ XAJ3 } & XAJ3F & CTCGTCTTTACCGTTCCGTCAAC & \multirow[t]{2}{*}{785} & Pseudomonas suwonensis 11-1 & \multirow{2}{*}{$\begin{array}{l}\text { Xanthomonas sp. Leaf } 148 \\
(1 \mathrm{e}-12 / 21 \%)\end{array}$} \\
\hline & XAJ3R & GCCCAAGGACATTCACACACTC & & $(6 e-16 / 10 \%)$ & \\
\hline \multirow[t]{2}{*}{ XAJ4 } & XAJ4F & TCGATCGAATCAGTAGTCACTGGC & \multirow[t]{2}{*}{748} & $\begin{array}{l}\text { Bifidobacterium animalis subsp. animalis } \\
\text { ATCC } 25527\end{array}$ & \multirow[t]{2}{*}{ X. hyacinthi DSM 19077} \\
\hline & XAJ4R & CGGATCTCTTCATTCGTCAGGTG & & $(0.26 / 5 \%)$ & \\
\hline \multirow[t]{2}{*}{ XAJ5 } & XAJ5F & AGCCTTGGGGTAGCTTTTGAGG & \multirow[t]{2}{*}{491} & Corynebacterium mustelae DSM 45274 & \multirow{2}{*}{$\begin{array}{l}\text { X. axonopodis pv. glycines CFBP } 7119 \\
(0 / 100 \%)\end{array}$} \\
\hline & XAJ5R & CGTTCTTTGACGGCACTCCC & & $(0.17 / 6 \%)$ & \\
\hline \multirow[t]{2}{*}{ XAJ6 } & XAJ6F & AAGTCAGATGCGAAGCGAAAGG & \multirow[t]{2}{*}{436} & Ascaris lumbricóides v1 54 & \multirow{2}{*}{$\begin{array}{l}\text { X. axonopodis pv. glycines CFBP } 7119 \\
(0 / 100 \%)\end{array}$} \\
\hline & XAJ6R & GCACAGCGGGAAGTAATAGCAAAC & & $(0.51 / 6 \%)$ & \\
\hline \multirow[t]{2}{*}{ XAJ7 } & XAJ7F & ATAACTACCACCAACTTCCTGGGG & \multirow[t]{2}{*}{766} & Alligator sinensis & \multirow{2}{*}{$\begin{array}{l}\text { X. arboricola pv. celebensis NCPPB } 1832 \\
(1 \mathrm{e}-133 / 35 \%)\end{array}$} \\
\hline & XAJ7R & TCTGGGCGAGGTAAGTGATTCTAC & & $(0.93 / 4 \%)$ & \\
\hline \multirow[t]{2}{*}{ XAJ8 } & XAJ8F & GGGGTGAAATCCAGTACCTGTCAC & \multirow[t]{2}{*}{588} & Monodelphis domestica & \multirow{2}{*}{$\begin{array}{l}\text { X. campestris pv. campestris Xca5 } \\
(8 \mathrm{e}-122 / 98 \%)\end{array}$} \\
\hline & XAJ8R & CGCAGAACGTACTTTCGGTACTGG & & $(2.5 / 4 \%)$ & \\
\hline \multirow[t]{2}{*}{ XAJ9 } & XAJ9F & CACGGGGATCAGCTTTTCATAC & \multirow[t]{2}{*}{443} & Ralstonia solanacearum & \multirow{2}{*}{$\begin{array}{l}\text { X. hortorum pv. carotae M081 } \\
(2 \mathrm{e}-166 / 83 \%)\end{array}$} \\
\hline & XAJ9R & GCGTCGGTAACGATGTTTTGTC & & $(1 \mathrm{e}-08 / 16 \%)$ & \\
\hline
\end{tabular}

${ }^{\mathrm{a}} \mathrm{Q}$ coverage $=$ query coverage . 
amplicons were sequenced in both strands and compared with gyrB sequences available in GenBank using the BLAST program.

To determine the phylogenetic relatedness of these isolates with other Xanthomonas spp., a maximum likelihood tree was built using the Tamura-Nei model in MEGA 6.0 (Tamura et al. 2013). The analysis was generated from the MUSCLE alignment of $145 \mathrm{gyr} B$ sequences (34 sequences of $X a j$ Portuguese isolates and 111 sequences representing different species of Xanthomonas).

Experimental validation of putative $X a j$-specific markers by dot blot. Validation of the nine putative $X a j$-specific markers across a large set of Xanthomonas spp. strains and isolates was carried out using a dot blot hybridization platform. DNA probes were prepared from the purified amplicons obtained from PCR amplifications using Xaj strain LMG 751 (= NCPPB 1447), from which the fully sequenced genome was used in this study to select the DNA markers. A $20 \mu \mathrm{l} \mathrm{PCR}$ reaction mix consisted of $1 \times$ DreamTaq Buffer (Fermentas), $0.2 \mathrm{mM}$ of each deoxynucleotide triphosphate (dNTP) (Fermentas), $0.2 \mu \mathrm{M}$ of each forward and reverse primers (Table 1), 1U of DreamTaq DNA Polymerase (Fermentas), and 25 ng of DNA template. PCR cycling parameters were carried out with the implementation of a first amplification cycle of $5 \mathrm{~min}$ at $95^{\circ} \mathrm{C}$, followed by 35 cycles of $95^{\circ} \mathrm{C}$ for $30 \mathrm{~s}$, $61^{\circ} \mathrm{C}$ for $30 \mathrm{~s}$, and $72^{\circ} \mathrm{C}$ for $30 \mathrm{~s}$, and a final DNA extension at $72^{\circ} \mathrm{C}$ for $10 \mathrm{~min}$. The identity of each amplicon, used as probe, was

Table 2. List of reference bacterial strains used for validation of Xanthomonas arboricola pv. juglandis specific markers

\begin{tabular}{|c|c|c|}
\hline Xanthomonas species and pathovars ${ }^{\mathbf{a}}$ & $\begin{array}{c}\text { Geographic } \\
\text { origin }\end{array}$ & $\begin{array}{c}\text { Year of } \\
\text { isolation }\end{array}$ \\
\hline X. arboricola pv. juglandis CFBP 176 & France & 1961 \\
\hline X. arboricola pv. juglandis CFBP 877 & France & 1966 \\
\hline X. arboricola pv. juglandis CFBP 2564 & Italy & 1985 \\
\hline X. arboricola pv. juglandis CFBP 2632 & Spain & 1984 \\
\hline X. arboricola pv. juglandis CFBP 5252 & France & 2000 \\
\hline X. arboricola pv. juglandis CFBP 6556 & Italy & 1993 \\
\hline X. arboricola pv. juglandis CFBP 6557 & Italy & 1999 \\
\hline X. arboricola pv. juglandis CFBP 7072 & Spain & 1993 \\
\hline X. arboricola pv. juglandis CFBP $7179^{\mathrm{GSS}}$ & France & 2002 \\
\hline X. arboricola pv. juglandis CFBP 7244 & France & 1978 \\
\hline X. arboricola pv. juglandis LMG 745 & Netherlands & 1978 \\
\hline X. arboricola pv. juglandis LMG 746 & United Kingdom & 1955 \\
\hline X. arboricola pv. juglandis LMG $747^{\mathrm{TS} ; \mathrm{GSS}}$ & New Zealand & 1956 \\
\hline X. arboricola pv. juglandis LMG 748 & New Zealand & 1956 \\
\hline X. arboricola pv. juglandis LMG 749 & New Zealand & 1957 \\
\hline X. arboricola pv. juglandis LMG $751^{\mathrm{GSS} ; *}$ & Romania & 1962 \\
\hline X. arboricola pv. juglandis LMG 752 & United Kingdom & 1964 \\
\hline X. arboricola pv. juglandis LMG 8047 & Netherlands & 1979 \\
\hline X. arboricola pv. celebensis $\mathrm{LMG} 677^{\mathrm{PRS}}$ & New Zealand & 1960 \\
\hline X. arboricola pv. corylina LMG $689^{\mathrm{PRS}}$ & United States & 1939 \\
\hline X. arboricola pv. fragariae LMG 19145 PRS & Italy & 1993 \\
\hline X. arboricola pv. populi CFBP $3123^{\text {PRS }}$ & Netherlands & 1979 \\
\hline$X$. arboricola pv. pruni LMG $852^{\mathrm{PRS}}$ & New Zealand & 1953 \\
\hline X. axonopodis pv. citri LMG $9322^{\mathrm{TS}}$ & United States & 1989 \\
\hline X. axonopodis pv. dieffenbachiae $\mathrm{LMG} 695^{\mathrm{PRS}}$ & Brazil & 1965 \\
\hline X. axonopodis pv. phaseoli $\mathrm{LMG} 7455^{\mathrm{PRS}}$ & United States & 1986 \\
\hline X. campestris pv. campestris LMG 568 & United Kingdom & 1957 \\
\hline X. euvesicatoria LMG 922 & United States & 1939 \\
\hline X. fragariae $\mathrm{LMG} 708^{\mathrm{TS}}$ & United States & 1960 \\
\hline X. gardneri LMG $962^{\mathrm{GSS} ; \mathrm{TS}}$ & Yugoslavia & 1953 \\
\hline X. oryzae pv. oryzae LMG $5047^{\mathrm{PRS}}$ & India & 1965 \\
\hline X. oryzae pv. oryzicola LMG $797^{\mathrm{PRS}}$ & Malaysia & 1964 \\
\hline X. perforans NCPPB $4321^{\mathrm{TS}}$ & United States & 1991 \\
\hline X. translucens pv. translucens $\mathrm{LMG} 876^{\mathrm{GSS} ; \mathrm{PRS}}$ & United States & 1933 \\
\hline X. vesicatoria LMG $911^{\mathrm{GSS}} ; \mathrm{TS}$ & New Zealand & 1955 \\
\hline
\end{tabular}

${ }^{a}$ CFBP: French Collection for Plant-associated Bacteria, Institut National de la Recherche Agronomique, Angers, France. LMG: Belgian Coordinated Collections of Microorganisms/ LMG Bacteria Collection, Universiteit Gent Laboratorium voor Microbiologie, Gent, Belgium. NCPPB: National Collection of Plant Pathogenic Bacteria, Fera Science Ltd., York, United Kingdom. *: other collection no: NCPPB 1447; TS, type strain; GSS, genome sequenced strain; PRS, pathovar reference strain. confirmed by sequencing. The obtained PCR products were purified using the illustra GFX GEL Band Purification kit (GE Healthcare, Buckingham-shire, United Kingdom), following the reference protocol available, and sequenced (STAB Vida, Caparica, Portugal).

Probes were labeled with digoxigenin using the DIG-High Prime kit, according to the manufacturer's instructions (Roche Diagnostics GmbH, Basel, Switzerland). For dot blot assays, $100 \mathrm{ng}$ of heat-denaturated bacterial DNA were spotted into nylon membranes (Roche Diagnostics GmbH, Basel, Switzerland) using a Bio-Dot apparatus (Bio-Rad, Hercules, CA). Each membrane was hybridized overnight at $68^{\circ} \mathrm{C}$ to ensure high stringency with a final probe concentration of $100 \mathrm{ng} / \mathrm{ml}$, and stringency washes were performed as described in the DIG application manual. Probe-target hybrids were detected with chemiluminescent alkaline phosphatase substrate (CDP-Star) reagent (Roche Diagnostics, Basel, Switzerland) and the images were acquired using a Molecular Imager ChemiDoc system (Bio-Rad, Hercules, CA).

Multiplex PCR validation. A multiplex PCR targeting the most promising $X a j$-specific markers was optimized in order to validate a method to rapidly identify $X a j$ isolates and for the direct diagnostics of Xaj infection in walnut tree samples. XAJ1, XAJ6, and XAJ8 were the chosen markers since they were shown to hybridize to most of the Xaj tested and have distinct amplicon lengths of 758, 436, and $588 \mathrm{bp}$, respectively. Multiplex PCR assays were performed on DNA extracted from bacterial strains/isolates and from plant tissue extracts. For chromosomal bacterial DNA, the PCR conditions were essentially the same as those used to obtain the DNA dot blot probes with an increase of DreamTaq DNA polymerase to $1.5 \mathrm{U}$ per PCR reaction. Concerning DNA extracted from infected plant material, PCR reactions were prepared with $2 \mu$ l of DNA extracted from infected walnut leaves and fruits using both the QIAGEN DNeasy Plant Mini kit and the CTAB-based DNA extraction as described above, and 1.5U of GoTAQ G2 Flexi DNA Polymerase (Promega, Madison, WI). For these samples, PCR amplification conditions were 10 initial PCR cycles at an annealing temperature of $55^{\circ} \mathrm{C}$, followed by 30 cycles at an annealing temperature of $61^{\circ} \mathrm{C}$. To further confirm multiplex PCR results from infected plant material, the same DNA samples were used as a template in PCR reactions using each of the markers individually (XAJ1, XAJ6, and XAJ8). PCR amplification of these three markers was performed as described to prepare the DNA dot blot probes.

Finally, to ensure that multiplex PCR amplification from symptomatic plant material was due to infection by Xaj, a multiplex PCR was carried out using the $X a j$ isolates obtained from the same infected plant samples. Partial sequencing of $g y r B$ confirmed the $X a j$ identity of these isolates. All the $436 \mathrm{bp}$ amplicons corresponding to the marker XAJ6 and obtained from both the plant samples and $X a j$ isolates were purified using the illustra GFX GEL Band Purification kit and sequenced to confirm their identity.

Detection limit of multiplex PCR. Sensitivity of multiplex PCR was determined with chromosomal DNA, bacterial suspensions, and spiked plant extracts using Xaj LMG 747. Chromosomal DNA multiplex PCR conditions were the same as described above for multiplex PCR validation with bacterial DNA template, using $2 \mu$ of each 10 -fold DNA dilutions ranging from $100 \mathrm{ng}$ to $10 \mathrm{fg}$. Multiplex PCR detection limit of cell suspensions was obtained from 10-fold dilutions, prepared in SDW, of Xaj LMG 747 cells grown for $48 \mathrm{~h}$ at $28 \pm$ $2^{\circ} \mathrm{C}$ on NA medium, within the range of $10^{8}$ to $10^{\circ} \mathrm{CFU} / \mathrm{ml}$. Five microliters of each dilution was used as DNA template for multiplex PCR reactions, which were carried out as described above but increasing the initial denaturation step to $10 \mathrm{~min}$ at $95^{\circ} \mathrm{C}$ to ensure bacterial cell lysis. The Xaj LMG 747 suspension of $10^{8} \mathrm{CFU} / \mathrm{ml}$ was also used to determine the multiplex PCR detection limit in spiked walnut leaf samples. Walnut leaf fragments (about $0.6 \mathrm{~g}$ ) were macerated as described previously. The resulting extract was used to prepare 10-fold serial dilutions of spiked walnut leaf samples ranging from $10^{7}$ down to $10^{0}$ $\mathrm{CFU} / \mathrm{ml}$. From each dilution, DNA was extracted using both CTABbased method and QIAGEN DNeasy Plant Mini kit as described above. Multiplex PCR was carried out as described for naturally infected plant material. 
Nucleotide sequences accession numbers. DNA sequences corresponding to the nine DNA markers (XAJ1 to XAJ9) were deposited in the NCBI database with the following accession numbers: KU577313 to KU577316 for XAJ1; KU577317 and KU577318 for XAJ2; KU577319 to KU577322 for XAJ3; KU577323 to KU577326 for XAJ4; KU577327 to KU577330 for XAJ5; KU577331 to KU577334 plus KX530957 for XAJ6; KU577335 to KU577337 for XAJ7; KU577338 to KU577341 for XAJ8; and KU577342 to KU577345 for XAJ9. NCBI accession numbers for $g y r B$ of Xaj Portuguese isolates are shown in Table 3.

\section{Results}

In silico selection of DNA markers specific for Xaj. The comprehensive BLAST analysis of all ORFs (>100 bp) inferred from the draft genome of Xaj (NCPPB 1447 = LMG 751; accession PRJNA84273) resulted in the selection of nine markers, designated as XAJ1 to XAJ9, which showed low identity (E value $>1 \mathrm{e}-10$; query coverage $<35 \%$ ) to sequences of non-xanthomonads species (Table 1). Significant BLAST wgs hits were obtained with Xanthomonas species, namely with $X$. arboricola pv. celebensis, $X$. perforans, $X$. axonopodis pv. glycines, $X$. campestris pv. campestris, and $X$. hortorum pv. carotae (Table 1 ). Concerning ORF identity, none of the markers could be unequivocally assigned to a well characterized gene of the reference genome (accession PRJNA84273), being either located in intergenomic regions or in genomic regions coding for hypothetical proteins (Supplementary Table S1).

gyrB sequencing analysis of $\mathrm{Xaj}$ isolates obtained from walnut samples. A set of 34 isolates was obtained from field samples of leaves and fruits from walnut trees exhibiting characteristic symptoms of WBB or/and BAN (Table 3). The assignment of all isolates into $X$. arboricola was confirmed by $\operatorname{gyr} B$ gene sequencing analysis In fact, all isolates showed higher sequence similarity to $X$. arboricola, with a BLAST E value of 0.0 and identity of 99 to $100 \%$. In addition, the maximum likelihood tree showed that within the genus Xanthomonas, all the isolates clustered together with other $X$. arboricola pathovars. Moreover, four isolates (CPBF 1507, CPBF 1508, CPBF 1514, and CPBF 1522) were grouped in a different cluster (Fig. 1).

Experimental validation of the selected markers by dot blot. The dot blot assays carried out using as probes the nine markers (XAJ1 to XAJ9) obtained from Xaj strain LMG 751, confirmed the specificity of the markers to $X a j$ since no hybridization was observed whatever the nontarget Xanthomonas spp. (Table 2) tested (data not shown), with exception of markers XAJ1 and XAJ7 that hybridized to $X$. arboricola pv. celebensis LMG 677 (Fig. 2), as predicted by the initial BLAST analysis (Table 1). Furthermore, from the $52 \mathrm{Xaj}$ strains/isolates tested, 12 distinct hybridization profiles, designated as HP1 to HP12, were observed (Fig. 2). These hybridization patterns varied from $X a j$ hybridizing with the nine markers (HP1), to an $X a j$ strain (CFBP 2632) hybridizing with two markers (HP12). While most of these hybridization patterns were present in two to six Xaj strains/ isolates (HP1, HP2, HP4, HP6, HP8, HP9, and HP11), one hybridization pattern was dominant and observed in $15 \mathrm{Xaj}$ (HP10) and four hybridization patterns were unique to single $X a j$ strains/isolates (HP3, HP5, HP7, and HP12). Concerning the efficacy of the markers, it is evident that XAJ1, XAJ4, XAJ6, and XAJ8 hybridized to most of the Xaj strains and isolates, with emphasis for XAJ1, which hybridized with all the $X a j$ tested. Although the remaining markers were unable to hybridize with some $X a j$ strains/isolates, it is important to acknowledge their

Table 3. List of bacterial isolates collected in Portugal used in this study and the correspondent GenBank accession number of partial gyrB sequences (835 bp)

\begin{tabular}{|c|c|c|c|c|}
\hline Isolates $^{\mathrm{a}}$ & Host plant & Isolation sources $^{\mathbf{b}}$ & Location, year & Accession number \\
\hline CPBF 1271 & Juglans regia & $\mathrm{n} / \mathrm{a}$ & Azeitão, 2009 & KU058325 \\
\hline CPBF 1479 & J. regia & Leaves & Azeitão, 2014 & KU058326 \\
\hline CPBF 1480 & J. regia & Fruits & Azeitão, 2014 & KU058327 \\
\hline CPBF 1484 & J. regia cv. Hartley & Leaves & Alcobaça, 2014 & KU058329 \\
\hline CPBF 1485 & J. regia cv. Hartley & Fruits & Alcobaça, 2014 & KU058330 \\
\hline CPBF 1486 & J. regia cv. Lara & Leaves & Alcobaça, 2014 & KU058331 \\
\hline CPBF 1487 & J. regia cv. Franquette & Leaves & Alcobaça, 2014 & KU058332 \\
\hline CPBF 1489 & J. regia cv. Rego & Leaves & Alcobaça, 2014 & KU058333 \\
\hline CPBF 1490 & J. regia cv. Rego & Fruits & Alcobaça, 2014 & KU058334 \\
\hline CPBF 1491 & J. regia cv. Corne & Fruits & Alcobaça, 2014 & KU058335 \\
\hline CPBF 1492 & J. regia cv. Amigo & Leaves & Alcobaça, 2014 & KU058336 \\
\hline CPBF 1496 & J. regia cv. Franquette & Fruits & Alcobaça, 2014 & KU058337 \\
\hline CPBF 1497 & J. regia cv. Corne & Leaves & Alcobaça, 2014 & KU058338 \\
\hline CPBF 1502 & J. regia cv. Hartley & Leaves & Alcobaça, 2014 & KU058339 \\
\hline CPBF 1503 & J. regia & Leaves & Seia, 2014 & KU058340 \\
\hline CPBF 1504 & J. regia & Leaves & Seia, 2014 & KU058341 \\
\hline CPBF 1505 & J. regia & Fruits & Seia, 2014 & KU058342 \\
\hline CPBF 1506 & J. regia & Fruits & Seia, 2014 & KU058343 \\
\hline CPBF 1507 & J. regia & Leaves & Beja, 2014 & KU058344 \\
\hline CPBF 1508 & J. regia & Leaves & Beja, 2014 & KU058345 \\
\hline CPBF 1509 & J. regia & Fruits & Azeitão, 2014 & KU058346 \\
\hline CPBF 1510 & J. regia & Fruits & Azeitão, 2014 & KU058347 \\
\hline CPBF 1511 & J. regia & Fruits & Azeitão, 2014 & KU058348 \\
\hline CPBF 1512 & J. regia & Leaves & Seia, 2014 & KU058349 \\
\hline CPBF 1513 & J. regia cv. Hartley & Leaves & Estremoz, 2014 & KU058350 \\
\hline CPBF 1514 & J. regia cv. Hartley & Leaves & Estremoz, 2014 & KU058351 \\
\hline CPBF 1518 & J. regia cv. Lara & Leaves & Estremoz, 2014 & KU058354 \\
\hline CPBF 1519 & $J$. regia $\mathrm{cv}$. Tulana & Leaves & Estremoz, 2014 & KU058355 \\
\hline CPBF 1520 & J. regia cv. Tulana & Leaves & Estremoz, 2014 & KU058356 \\
\hline CPBF 1521 & J. regia & Leaves & Loures, 2014 & KU058357 \\
\hline CPBF 1522 & J. regia cv. Howard & Leaves & Estremoz, 2014 & KU058358 \\
\hline CPBF 1525 & J. regia cv. Lara & Leaves & Estremoz, 2014 & KU058359 \\
\hline CPBF 1526 & J. regia cv. Lara & Leaves & Estremoz, 2014 & KU058360 \\
\hline CPBF 1527 & J. regia cv. Lara & Leaves & Estremoz, 2014 & KU058361 \\
\hline
\end{tabular}

${ }^{a}$ CPBF: Colecção Portuguesa de Bactérias Fitopatogénicas, Instituto Nacional de Investigação Agrária e Veterinária, Oeiras, Portugal.

$\mathrm{b}$ n/a: not available. 
utility to obtain distinct hybridization patterns. For instance, the Xaj broad spectrum markers XAJ4, XAJ6, and XAJ8 did not hybridize with the group of $X a j$ strains and isolates sharing exactly the same hybridization pattern, i.e., HP9 and HP12 for marker XAJ4, HP11 for marker XAJ6, and HP8 and HP11 for marker XAJ8 (Fig. 2).

Multiplex PCR for identification of $X a j$ isolates and direct detection in infected walnut leaves and fruits. Reliable identification of putative $X a j$ isolates by multiplex PCR was optimized for markers XAJ1, XAJ6, and XAJ8. The multiplex PCR was validated with DNA extracted from all the strains and isolates listed in Tables 2 and 3, respectively. The results showed three distinct amplification profiles: amplification of the three markers for most Xaj strains/ isolates (41 out of 52); amplification of two markers (XAJ1 and XAJ6) for one Xaj strain (CFBP 2632) and five Xaj isolates (CPBF 1484, CPBF 1485, CPBF 1486, CPBF 1487, and CPBF 1496); and amplification of a single marker (XAJ1) for four isolates (CPBF
1507, CPBF 1508, CPBF 1514, and CPBF 1522). As expected, whatever the marker, no specific amplification was obtained with any representative of other Xanthomonas species and with any other $X$. arboricola pathovars (pv. corylina, pv. fragariae, pv. populi, and pv. pruni), with exception of pv. celebensis (LMG 677) for which marker XAJ1 was amplified (Supplementary Fig. S1). Interestingly, the larger amplicon (with 1,669 bp) observed for isolate CPBF 1497 was confirmed to correspond to marker XAJ6. Sequencing analysis of this amplicon (accession no. KX530957) revealed the insertion of a gene coding for a transposase within marker XAJ6. Altogether, these multiplex PCR results corroborated the dot blot patterns obtained with these three markers. In fact, matching results were observed for dot blot patterns and multiplex PCR for all the Xaj strains/isolates tested, including the $X$. arboricola pv. celebensis (LMG 677) the only non-juglandis pathovar strain for which amplification/hybridization of marker XAJ1 was observed.

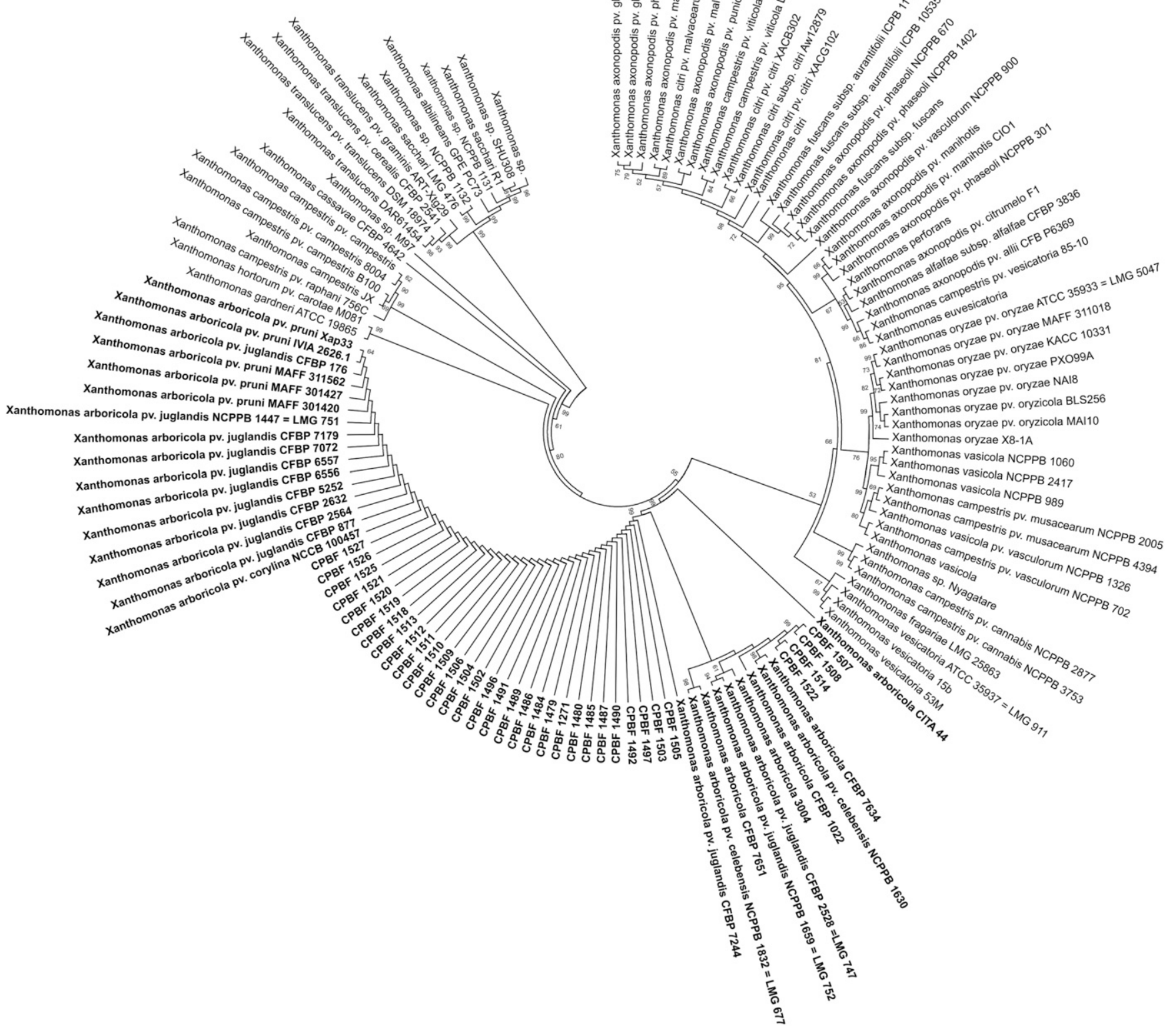

Fig. 1. Phylogenetic analysis based on 145 gyrB sequences of Xanthomonas species, including Xanthomonas arboricola isolates studied in this work. The tree was constructed according the maximum likelihood method and Tamura-nei model using MEGA 6.06. Bootstrap values higher than 50 are shown. $X$. arboricola strains and Portuguese isolates are highlighted in bold. 
Multiplex PCR was also able to detect Xaj in DNA extracted from naturally infected walnut leaves and fruits (Fig. 3). Indeed, marker XAJ6 was efficiently amplified for the 11 plant samples assayed, regardless the DNA extraction procedure and plant organ, i.e., infected leaves (L1 to L5) or fruits (F1 to F6). Marker XAJ1 was amplified for all samples, with the exception of F6, and its amplification efficiency was higher for infected fruit samples and using CTAB-based DNA extraction. Marker XAJ8 was clearly less efficient, with positive amplification for five out of six fruit samples, and no amplification observed for F6. Regarding the leaf samples, this marker showed low efficiency in multiplex PCR with no amplification for most of the samples and poor amplification in sample L1. Faint nonspecific PCR bands were also observed for some samples. The efficiency of each of these three markers was higher in single PCR reactions for each the 11 plant samples assayed, particularly for the samples where no amplification was obtained with the multiplex PCR, emphasizing the utility of single PCR reactions to resolve the lower efficiency of multiplex PCR particularly observed with leaf samples and marker XAJ8 (Fig. 3).

In parallel, to demonstrate that plant samples were infected by $X a j$, at least one putative $X a j$ isolate obtained from each of these infected leaves samples (L1 to L5) was screened for the presence of the XAJ6 marker and further identified by gyrB sequencing (Supplementary
Fig. S2). With exception for the Xaj putative isolate obtained from L1 sample, for which no XAJ6 and gyrB amplification was obtained, all the other isolates were positive for marker XAJ6 and gyrB. Sequence analysis of both XAJ6 and $g y r B$ for each of these isolates (L2 to L5) further confirmed their identity as $X$. arboricola. Taken together, these results underline the robustness of multiplex PCR for the direct detection of $X a j$ in symptomatic walnut leaves.

Multiplex PCR sensitivity. The detection limit of multiplex PCR targeting the specific Xaj markers XAJ1, XAJ6, and XAJ8, determined by serial dilution of chromosomal DNA, bacterial cell suspensions, and spiked plant extracts, was $20 \mathrm{pg}$ DNA $(10 \mathrm{pg} / \mu \mathrm{l}), 10^{4}$ $\mathrm{CFU} / \mathrm{ml}$, and $10^{3} \mathrm{CFU} / \mathrm{ml}$, respectively (Supplementary Fig. S3).

\section{Discussion}

Aiming to develop robust and culture-independent DNA-based approaches for identification of $X a j$ isolates and in planta detection of $X a j$, several specific DNA loci were selected based on a thorough BLAST analysis of the first $X a j$ draft genome made available (accession PRJNA84273). The putative $X a j$-specific loci were then filtered to infer their suitability as DNA markers considering their genomic stability and detection by PCR or dot blot hybridization, as previously described (Albuquerque et al. 2012).

Xanthomonas arboricola pv. juglandis strains and isolates

Xanthomonas arboricola strains

\section{$\vdash$}

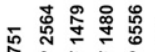

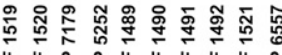

Fig. 2. Dot blot validation of Xanthomonas arboricola pv. juglandis (Xaj) specific markers (XAJ1 to XAJ9). Markers were tested across 18 Xaj reference strains, 34 Xaj isolates, and five non-juglandis pathovars of $X$. arboricola (Tables 1 and 2). Twelve different hybridization patterns (HP1 to HP12) were identified. The strain LMG 751 was used as positive hybridization control, and 13 non-arboricola Xanthomonas species (Table 2) were used as negative hybridization control (data not shown). DNA probes for the nine markers were prepared from the purified amplicons obtained from PCR amplifications using Xaj strain LMG 751 (= NCPPB 1447).

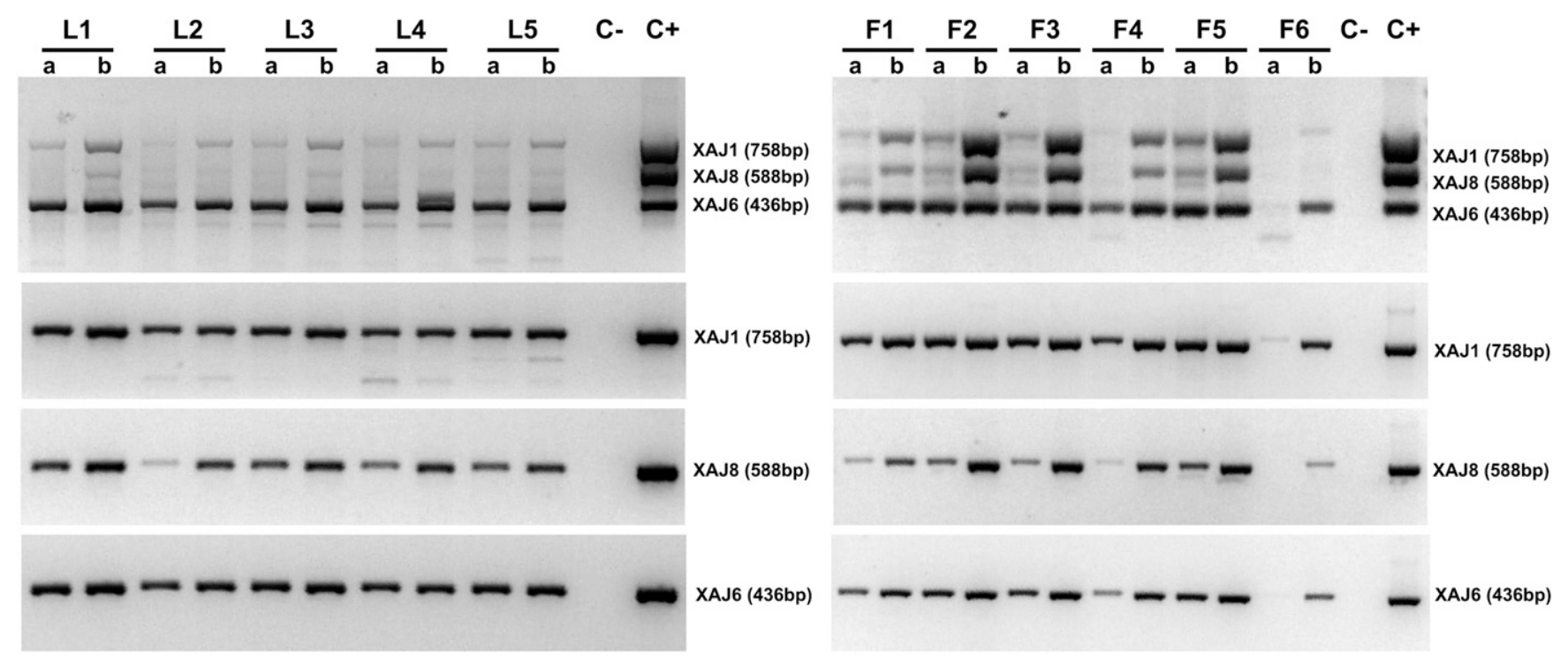

Fig. 3. Multiplex and single PCR reactions for detection of Xanthomonas arboricola pv. juglandis in naturally infected walnut leaves (L1 to $L 5)$ and fruits (F1 to $F 6)$ using three markers, XAJ1 (758 bp), XAJ6 (436 bp), and XAJ8 (588 bp). Each number represents a different walnut (Juglans regia) tree. For each sample, two PCR reactions were carried out, one using DNA extracted with the QIAGEN DNeasy Plant Mini kit (a), and the other with a CTAB-based DNA extraction procedure (b). For all the samples the identity of XAJ6 marker was confirmed by sequencing. Strain LMG 751 was used as positive control $\left(\mathrm{C}_{+}\right)$. 
The BLAST analysis revealed that the selected markers (XAJ1 to XAJ9), despite the low query coverage for markers XAJ4 and XAJ7, shared similarity with other Xanthomonas species (Table 1, wgs blast). Significant BLAST hits were obtained with other plant pathogens never identified from walnut, such as $X$. arboricola pv. celebensis (a banana plant pathogen), X. perforans (associated with tomato bacterial spot disease), $X$. axonopodis pv. glycines (causal agent of bacterial pustule of soybeans), X. campestris pv. campestris (attacks Brassica spp., responsible for the black rot of crucifers), and $X$. hortorum pv. carotae (a bacterial pathogen of carrot). The fact that these Xanthomonas spp. do not share the same ecological niche with Xaj (Hayward 1993; Leyns et al. 1984) supports the adequacy of these markers to establish new molecular methodologies of detection and identification. Meanwhile, a complementary BLAST search revealed the presence of these markers, with exception for marker $\mathrm{XAJ} 2$, in the recently released $\mathrm{Xaj}$ genomes (Cesbron et al. 2015; Higuera et al. 2015; Pereira et al. 2015).

In addition to the BLAST analysis, a validation by dot blot hybridization was carried out in order to confirm the consistency and specificity of the nine markers across a broad range of xanthomonads (Fig. 2). All the $18 \mathrm{Xaj}$ strains and $34 \mathrm{Xaj}$ isolates clustered into 12 different hybridization profiles, varying from hybridization with all the nine markers corresponding to HP1 (strains LMG 751 and CFBP 2564; Portuguese isolates CPBF 1479 and 1480), to hybridization with only two markers corresponding to HP12 (strain CFBP 2632). No evident relatedness was observed between these hybridization patterns and the geographic origin from which the isolates were obtained. Indeed, isolates from the same location displayed different hybridization profiles (e.g., HP4 for CPBF 1489 and HP10 for CPBF 1502 from Alcobaça), and inversely, identical hybridization patterns were found for isolates from distinct locations (e.g., HP10 for the isolates CPBF 1510 from Azeitão and CPBF 1513 from Estremoz). Taken together, these results demonstrate the utility of this dot blot platform to disclose the high genomic diversity of $X a j$, as reported by several genotyping studies (Essakhi et al. 2015; Giovanardi et al. 2016; Hajri et al. 2010, 2012; Ivanović et al. 2015; Kałużna et al. 2014; Loreti et al. 2001; Marcelletti et al. 2010; Scortichini et al. 2001). Most importantly, the distinct hybridization patterns can be informative to characterize different $X a j$ lineages, which can be particularly convenient before carrying out laborious fine tune methods of genotyping such as multilocus sequence analysis (MLSA) and multilocus sequence typing (MLST), or full genome sequencing.

When looking at the dot blot efficacy, it is evident that markers XAJ1, XAJ4, XAJ6, and XAJ8 hybridized with most of the Xaj strains tested (Fig. 2) and should be primary choices for detection and identification of Xaj. Interestingly, the $X a j$ isolates that did not hybridize to markers XAJ4, XAJ6, and XAJ8 shared identical hybridization profiles, suggesting that the genotype of these markers might be determined by either their presence or absence. In this regard, it is worth mentioning that the four $X a j$ isolates (CPBF $1507,1508,1514$, and 1522) corresponding to HP11 were PCR positive exclusively to marker XAJ1 in the multiplex assay as expected, and clustered together in the gyrB tree (Fig. 1).

The specificity of the selected markers to Xaj was shown by the fact that none of the nine markers hybridized with the 12 nonarboricola strains of Xanthomonas spp., or to any of the other five $X$. arboricola pathovars studied, with exception for $X$. arboricola pv. celebensis LMG 677, which hybridized to markers XAJ1 and XAJ7, confirming the blast wgs analysis (Table 1).

Currently, only a PCR method has been reported for identification of Xaj isolates (Gironde et al. 2009). Although this PCR approach has been used in recent studies (Burokiene and Pulawska 2012; Ivanović et al. 2015; Kałużna et al. 2014), the method is based on a single DNA marker and the sequence of the primers has not been published, undermining the full assessment of this method, namely in infected plant material. In this work, we propose a triplex PCR using markers XAJ1, XAJ6, and XAJ8, optimized to ensure an efficient, reliable, and rapid method to identify $X a j$ isolates, as well as for cultureindependent detection of $X a j$ in plant samples. These three markers were chosen due to their different amplicon sizes and their consistency across the different $X a j$ strains (Fig. 2). The validation of the multiplex
PCR was carried out with DNA extracted from all the $X a j$ strains and isolates, other pathovars of $X$. arboricola, and non-arboricola species of Xanthomonas included in this work (Tables 2 and 3). The PCR multiplex results fully confirmed the dot blot data, i.e., amplification was observed for any of the three markers, whenever the dot blot was positive for the corresponding marker, and whatever the $X a j$ strain or isolate tested. It should be noted that a simplex PCR using marker XAJ1 would also be satisfactory for routine detection of Xaj in infected plant samples, since this marker is highly specific and present throughout all tested Xaj strains. However, the higher detection confidence provided by the use of three independent markers cannot be underestimated, especially when considering Xaj diversity.

PCR based methods can be a valuable approach for direct detection of $X a j$ in plant tissues, allowing a rapid and cultureindependent detection of $X a j$ in walnuts, relevant for an early diagnosis of $\mathrm{WBB}$ or BAN and to determine the bacteria life cycle overwinter. In this study, we were able to amplify the markers XAJ1, XAJ6, and XAJ8 in DNA extracted from naturally infected walnut leaves and fruits indicating the presence of Xaj (Fig. 3). It has been acknowledged that the quality, purity, and quantity of DNA can impair the detection in plant material (Demeke and Jenkins 2010; López et al. 2003). The multiplex efficiency, particularly low for the larger markers (XAJ1 and XAJ8), could be related with the presence of plant-derived compounds or even treatment derived chemicals that may interfere with the amplification (Schrader et al. 2012). The higher efficiency observed for DNA extracted using the CTAB procedure in comparison with DNeasy, and for fruit samples rather than for leaves, seems to support this hypothesis. Furthermore, when the three markers were amplified in independent PCR reactions, markers' efficiency increased considerably, whatever the plant material and the DNA extraction procedure (Fig. 3). The faint unspecific amplifications observed in the multiplex PCR were likely favored by the lower annealing temperature, since most of these unspecific bands disappeared in the single PCR amplification of each marker (Fig. 3). The detection threshold of multiplex PCR for chromosomal DNA $(10 \mathrm{pg} / \mu \mathrm{l})$ and bacterial cells $\left(10^{4} \mathrm{CFU} / \mathrm{ml}\right.$ corresponding to 50 cells per reaction) are within the sensitivity range of multiplex PCR for other Xanthomonas spp. (Araújo et al. 2012; Pothier et al. 2011; Toth et al. 1998). In addition, the multiplex PCR detection limit of $10^{3} \mathrm{CFU} / \mathrm{ml} \mathrm{Xaj}$ in spiked walnut samples (i.e., two cells per reaction) demonstrate that the load of Xaj cells in field infected walnut leaves and fruits (Fig. 3) are well above this detection limit, which strengthens the effectiveness of this method for routine detection and to access $X a j$ in latently infected plant material (Hayward 1974).

In conclusion, this work proposes nine novel molecular markers for identification of $\mathrm{Xaj}$ isolates and its detection in infected plant samples using a dot blot hybridization assay or multiplex PCR. While four markers (XAJ1, XAJ4, XAJ6, XAJ8) were shown to be particularly effective, since they were detected in most of the Xaj tested, regardless of their genetic diversity, the other five markers, although clearly specific to $X a j$, displayed a narrower, but complementary detection range. Beyond the usefulness of these markers to identify and discriminate different $X a j$ lineages, we demonstrated that the broad range markers XAJ1, XAJ6, and XAJ8 might be used in cultureindependent approaches. Attending that direct detection of Xaj in plant material has never been described, these results are a promising contribution for the early and reliable diagnostics of walnut diseases caused by Xaj.

\section{Acknowledgments}

This work was co-financed by the European Structural \& Investment Funds (ESIFs) through the Operational Competitiveness and Internationalization Programme - COMPETE 2020 and by National Funds through FCT - Foundation for Science and Technology, within the framework of the project EVOXANT (PTDC/BIA-EVF/3635/2014). Pedro Albuquerque was supported by the project 'Genomics Applied to Genetic Resources' co-financed by North Portugal Regional Operational Programme 2007/2013 (ON.2 - O Novo Norte), under the National Strategic Reference Framework (NSRF), through the European Regional Development Fund (ERDF). Camila Fernandes is supported by a fellowship from the FCT (SFRH/BD/95913/2013). The authors would like to thank the walnut producers who collaborated in this study, Cláudia Serra for helpful discussions and to Paula Sá-Pereira for the fruitful comments made on the manuscript. 


\section{Literature Cited}

Albuquerque, P., Caridade, C. M. R., Rodrigues, A. S., Marcal, A. R. S., Cruz, J., Cruz, L., Santos, C. L., Mendes, M. V., and Tavares, F. 2012. Evolutionary and experimental assessment of novel markers for detection of Xanthomonas euvesicatoria in plant samples. PLoS One 7:e37836.

Allen, C., Bent, A., and Charkowski, A. 2009. Underexplored niches in research on plant pathogenic bacteria. Plant Physiol. 150:1631-1637.

Altschul, S. F., Gish, W., Miller, W., Myers, E. W., and Lipman, D. J. 1990. Basic local alignment search tool. J. Mol. Biol. 215:403-410.

Araújo, E. R., Costa, J. R., Ferreira, M. A. S. V., and Quezado-Duval, A. M. 2012. Simultaneous detection and identification of the Xanthomonas species complex associated with tomato bacterial spot using species-specific primers and multiplex PCR. J. Appl. Microbiol. 113:1479-1490.

Belisario, A., Maccaroni, M., Corazza, L., Balmas, V., and Valier, A. 2002. Occurrence and etiology of brown apical necrosis on Persian (English) walnut fruit. Plant Dis. 86:599-602.

Burokiene, D. and J.Pulawska 2012. Characterization of Xanthomonas arboricola pv. juglandis isolated from walnuts in Lithuania. J. Plant Pathol. 94: S1.23-S1.27.

Cesbron, S., Briand, M., Essakhi, S., Gironde, S., Boureau, T., Manceau, C., Fischer-Le Saux, M., and Jacques, M. A. 2015. Comparative genomics of pathogenic and nonpathogenic strains of Xanthomonas arboricola unveil molecular and evolutionary events linked to pathoadaptation. Front. Plant Sci. 6:1126.

Demeke, T., and Jenkins, G. R. 2010. Influence of DNA extraction methods, PCR inhibitors and quantification methods on real-time PCR assay of biotechnologyderived traits. Anal. Bioanal. Chem. 396:1977-1990.

Doyle, J. 1991. Pages 283-293 in: DNA protocols for plants. Molecular Techniques in Taxonomy. G. M. Hewitt, A. W. B. Johnston, and J. P. W. Young, eds. Springer Berlin Heidelberg, Berlin, Heidelberg.

Essakhi, S., Cesbron, S., Fischer-Le Saux, M., Bonneau, S., Jacques, M. A., and Manceau, C. 2015. Phylogenetic and variable-number tandem-repeat analyses identify nonpathogenic Xanthomonas arboricola lineages lacking the canonical type III secretion system. Appl. Environ. Microbiol. 81:5395-5410.

Fischer-Le Saux, M., Bonneau, S., Essakhi, S., Manceau, C., and Jacques, M. A. 2015. Aggressive emerging pathovars of Xanthomonas arboricola represent widespread epidemic clones distinct from poorly pathogenic strains, as revealed by multilocus sequence typing. Appl. Environ. Microbiol. 81:4651-4668.

Frutos, D. 2010. Bacterial diseases of walnut and hazelnut and genetic resources. J. Plant Pathol. 92:S79-S85.

Giovanardi, D., Bonneau, S., Gironde, S., Fischer-Le Saux, M., Manceau, C., and Stefani, E. 2016. Morphological and genotypic features of Xanthomonas arboricola pv. juglandis populations from walnut groves in Romagna region, Italy. Eur. J. Plant Pathol. 145:1-16.

Gironde, S., Guillaumes, J., and Manceau, C. (2009). Specific detection of Xanthomonas arboricola pv. juglandis pathogen on walnut. EPPO Conference on Diagnostics and Associated workshops, York, U.K.

Hajri, A., Meyer, D., Delort, F., Guillaumes, J., Brin, C., and Manceau, C. 2010. Identification of a genetic lineage within Xanthomonas arboricola pv. juglandis as the causal agent of vertical oozing canker of Persian (English) walnut in France. Plant Pathol. 59:1014-1022.

Hajri, A., Pothier, J. F., Fischer-Le Saux, M., Bonneau, S., Poussier, S., Boureau, T., Duffy, B., and Manceau, C. 2012. Type three effector gene distribution and sequence analysis provide new insights into the pathogenicity of plantpathogenic Xanthomonas arboricola. Appl. Environ. Microbiol. 78:371-384.

Hayward, A. C. 1974. Latent infections by bacteria. Annu. Rev. Phytopathol. 12: 87-97.

Hayward, A. C. 1993. The hosts of Xanthomonas. Pages 1-119 in: Xanthomonas. J. G. Swings and E. L. Civerolo, eds. Chapman \& Hall, London.

Higuera, G., Gonzalez-Escalona, N., Veliz, C., Vera, F., and Romero, J. 2015. Draft genome sequences of four Xanthomonas arboricola pv. juglandis strains associated with walnut blight in Chile. Genome Announc. 3:e01160-15.

Ivanović, Z., Popović, T., Janse, J., Kojić, M., Stanković, S., Gavrilović, V., and Fira, D. 2015. Molecular assessment of genetic diversity of Xanthomonas arboricola pv. juglandis strains from Serbia by various DNA fingerprinting techniques. Eur. J. Plant Pathol. 141:133-145.

Janse, J. 2010. Diagnostic methods for phytopathogenic bacteria of stone fruits and nuts in COST 873. EPPO Bull. 40:68-85.

Janse, J., Rossi, M., Gorkink, R., Derks, J., Swings, J., Janssens, D., and Scortichini, M. 2001. Bacterial leaf blight of strawberry (Fragaria $(\times)$ ananassa) caused by a pathovar of Xanthomonas arboricola, not similar to
Xanthomonas fragariae Kennedy \& King. Description of the causal organism as Xanthomonas arboricola pv. fragariae (pv. nov., comb. nov.). Plant Pathol. 50:653-665.

Kałużna, M., Pulawska, J., Waleron, M., and Sobiczewski, P. 2014. The genetic characterization of Xanthomonas arboricola pv. juglandis, the causal agent of walnut blight in Poland. Plant Pathol. 63:1404-1416.

Lamichhane, J. R. 2014. Xanthomonas arboricola diseases of stone fruit, almond, and walnut trees: Progress toward understanding and management. Plant Dis. 98:1600-1610.

Lelliott, R. A., and Stead, D. E. 1987. Methods for the diagnosis of bacterial diseases of plants. In: Methods in Plant Pathology Vol. 2. T. F. Preece Series, British Society of Plant Pathology, Blackwell Scientific Publications, Oxford.

Leyns, F., Decleene, M., Swings, J. G., and Deley, J. 1984. The host range of the genus Xanthomonas. Bot. Rev. 50:308-356.

Lindow, S., Olson, W., and Buchner, R. 2014. Colonization of dormant walnut buds by Xanthomonas arboricola pv. juglandis is predictive of subsequent disease. Phytopathology 104:1163-1174.

López, M. M., Bertolini, E., Olmos, A., Caruso, P., Gorris, M. T., Llop, P., Penyalver, R., and Cambra, M. 2003. Innovative tools for detection of plant pathogenic viruses and bacteria. Int. Microbiol. 6:233-243.

Loreti, S., Gallelli, A., Belisario, A., Wajnberg, E., and Corazza, L. 2001. Investigation of genomic variability of Xanthomonas arboricola pv. juglandis by AFLP analysis. Eur. J. Plant Pathol. 107:583-591.

Marcelletti, S., Ferrante, P., and Scortichini, M. 2010. Multilocus sequence typing reveals relevant genetic variation and different evolutionary dynamics among strains of Xanthomonas arboricola pv. juglandis. Diversity (Basel) 2:1205.

Moragrega, C. 2012. Detection and identification methods and new tests as developed and used in the framework of COST 873 for bacteria pathogenic to stone fruits and nuts: Xanthomonas arboricola pv. juglandis. J. Plant Pathol. 94:S1.155-S1.159.

Moragrega, C., Matias, J., Aleta, N., Montesinos, E., and Rovira, M. 2011. Apical necrosis and premature drop of Persian (English) walnut fruit caused by Xanthomonas arboricola pv. juglandis. Plant Dis. 95:1565-1570.

Moragrega, C., and Ozaktan, H. 2010. Apical necrosis of Persian (English) walnut (Juglans regia): An update. J. Plant Pathol. 92:S67-S71.

Mulrean, E. N., and Schroth, M. N. 1982. Ecology of Xanthomonas campestris pv. juglandis on Persin (English) walnuts. Phytopathology 72:434-438.

Murray, M. G., and Thompson, W. F. 1980. Rapid isolation of high molecularweight plant DNA. Nucleic Acids Res. 8:4321-4326.

Pereira, U. P., Gouran, H., Nascimento, R., Adaskaveg, J. E., Goulart, L. R., and Dandekar, A. M. 2015. Complete genome sequence of Xanthomonas arboricola pv. juglandis 417, a copper-resistant strain isolated from Juglans regia $\mathrm{L}$. Genome Announc. 3:e1126-15.

Pierce, N. B. 1901. Walnut bacteriosis. Bot. Gaz. 31:272-273.

Pothier, J. F., Pagani, M. C., Pelludat, C., Ritchie, D. F., and Duffy, B. 2011. A duplex-PCR method for species-and pathovar-level identification and detection of the quarantine plant pathogen Xanthomonas arboricola pv. pruni. J. Microbiol. Methods 86:16-24.

Schrader, C., Schielke, A., Ellerbroek, L., and Johne, R. 2012. PCR inhibitorsoccurrence, properties and removal. J. Appl. Microbiol. 113:1014-1026.

Scortichini, M. 2010. Epidemiology and predisposing factors of some major bacterial diseases of stone and nut fruit trees species. J. Plant Pathol. 92: S73-S78.

Scortichini, M., Marchesi, U., and Di Prospero, P. 2001. Genetic diversity of Xanthomonas arboricola pv. juglandis (synonyms: $X$-campestris pv. juglandis; $X$-juglandis pv. juglandis) strains from different geographical areas shown by repetitive polymerase chain reaction genomic fingerprinting. J. Phytopathol. 149:325-332.

Smith, R. E., Smith, C. O., and Ramsey, H. J. 1912. Walnut culture in California: walnut blight. Supt. of State printing, Sacramento, CA.

Tamura, K., Stecher, G., Peterson, D., Filipski, A., and Kumar, S. 2013. MEGA6: Molecular Evolutionary Genetics Analysis Version 6.0. Mol. Biol. Evol. 30: $2725-2729$.

Toth, I. K., Hyman, L. J., Taylor, R., and Birch, P. R. J. 1998. PCR-based detection of Xanthomonas campestris pv. phaseoli var. fuscans in plant material and its differentiation from X. c. pv. phaseoli. J. Appl. Microbiol. 85:327-336.

Vauterin, L., Hoste, B., Kersters, K., and Swings, J. 1995. Reclassification of Xanthomonas. Int. J. Syst. Bacteriol. 45:472-489.

Young, J. M., Park, D. C., Shearman, H. M., and Fargier, E. 2008. A multilocus sequence analysis of the genus Xanthomonas. Syst. Appl. Microbiol. 31: 366-377. 